\title{
Perspectives of Information Systems
}


Springer-Science+Business Media, LLC 
Vesa Savolainen

Editor and Main Author

\section{Perspectives of Information Systems}




\author{
Vesa Savolainen \\ Department of Computer Science \\ and Information Systems \\ University of Jyväskylä \\ Jyväskylä FIN-40351 \\ Finland \\ vesa@cs.jyu.fi
}

Library of Congress Cataloging-in-Publication Data

Savolainen, Vesa.

Perspectives of Information Systems / Vesa Savolainen

p. $\quad \mathrm{cm}$.

Includes bibliographical references (p. ).

ISBN 978-1-4612-7153-6 ISBN 978-1-4612-1464-9 (eBook)
DOI 10.1007/978-1-4612-1464-9

1. Information technology. I. Title.

T58.5.S29 1999

$658.4^{\prime} 038^{\prime} 011-\mathrm{dc} 21$

$98-53848$

Printed on acid-free paper.

(C) 1999 Springer Science+Business Media New York

Originally published by Springer-Verlag New York Berlin Heidelberg in 1999

Softcover reprint of the hardcover 1st edition 1999

All rights reserved. This work may not be translated or copied in whole or in part without the written permission of the publisher (Springer Science+Business Media, LLC), except for brief excerpts in connection with reviews or scholarly analysis. Use in connection with any form of information storage and retrieval, electronic adaptation, computer software, or by similar or dissimilar methodology now known or hereafter developed is forbidden. The use of general descriptive names, trade names, trademarks, etc., in this publication, even if the former are not especially identified, is not to be taken as a sign that such names, as understood by the Trade Marks and Merchandise Marks Act, may accordingly be used freely by anyone.

Production managed by A. Orrantia; manufacturing supervised by Thomas King.

Typeset by The Laura Carlson Co., Yellow Springs, OH.

987654321

ISBN 978-1-4612-7153-6 
For Anneli, Simo, and Petri 


\section{Preface}

Information system science, defined broadly, is highly interdisciplinary because it can be seen as the effective analysis, design, delivery, use, and impact of information technology in organizations and society. Many basic as well as advanced books on information systems and their development apply approaches and theories from such disciplines as technology, management science, economics, mathematics, psychology, sociology, and philosophy. Such new branches of information system science as mobile information systems, multimedia information systems, telematic commerce, and cooperative work support systems have incorporated theories from such disciplines as organization science, education sciences, communication science, and musicology.

\section{Objectives and Uses of This Book}

This book focuses on various issues in information systems and their development, as well as on the advanced utilization of new information technology. The fields and issues that are analyzed in this book have not been discussed in the same context in the current scientific literature, although they are becoming more important in information systems development. This book includes both theoretical foundations and practical approaches for each topic, and therefore it is of relevance both to scientists of information systems and to practitioners in information systems development, introduction, and use. Large companies and software houses will also find this book useful in its discussion of methods for evaluating information technologies, systems, methodologies, and tools. Our colleagues have expressed a need for this kind of book.

We offer new perspectives on key topics in information systems research. These topics and research results are especially useful today because of the rapidly changing nature of information systems and information technology. Methodologies and metamodels for information system development (ISD) and their evaluation, contingency factors and uncertainty in decision making in ISD, development of holistic ISD methodologies, selection of ISD methods and tools, intel- 
ligent executive information systems, mobile information systems, exception handling in information systems, and quality assurance and dynamic performance evaluation of information systems are topics that are not often discussed in the literature but are today considered essential in this field. We emphasize the basic approach of information systems scientists, that is the needs of the endusers and the organization as the starting point of information system development and introduction. Contingency, user-participation and evaluation are also considered of importance throughout the text.

Thus, one of the outstanding features of this book is its mixture of subjects under one framework of thinking about information system science. The fundamental ideas of this conceptual framework have resulted in many features of two multinational ESPRIT (European Strategic Programme for Research and Development in Information Technology) projects in the European Union: OSSAD (Office Support Systems Analysis and Design) and HECTOR (Harmonized European Concepts and Tools for Organizational Information Systems).

The editor and main author has participated in the development of each chapter. The book will be useful both in practice and as part of the academic information system (IS) curricula at universities. This material has been successfully used in the advanced course on information systems development at the University of Jyväskylä in Finland, where the editor teaches.

\section{Organization and Contents}

Although the basic framework of our thinking can be found in the first two parts of the book and subsequent parts are based on these approaches, definitions, and models, we designed the book to allow the reader to jump around between parts and chapters. Each chapter is self-contained and does not necessarily require having read the previous chapters.

The book is divided into seven parts. Parts I and II provide the conceptual framework. In Chapter 1, we define the conceptual components of an information system. These components, together with the principles of systems-theoretical control structure and linguistic abstraction, are employed in constructing a hierarchical multilevel universal framework for information activities in an organization. The framework lays the foundation for the analysis, modeling, and evaluation of information systems and their relevance for information activities in an organization.

Chapter 2 compares three reference frameworks for information systems and discusses their development. The analysis and comparison scheme is derived from a definition of the concepts of ISD methodology and metamethodology. This detailed scheme is used to determine the strengths and weaknesses of the reference frameworks, but it can also be used in the same way as the frameworks themselves, that is, as a basis for comparing ISD methodologies.

Contingency factors and management of uncertainty in decision making in the introduction of information technology are analyzed and discussed in Chapter 3. 
It is of great importance for the decision maker to know the preconditions and the overall favorable atmosphere that should prevail for effective and successful information technology decision making in an organization.

Part III discusses ISD methodologies, methods and tools. The OSSAD methodology was constructed to guide the analysis and design of office organizations and office support systems (Chapter 4). It offers tools, procedures, and practices for finding balanced solutions to social and technical problems in office environments in order to realize acceptable, effective and efficient office support systems in a way that is best suited to their use environment. Its main principles are strong contingency, user participation and modeling. This methodology was created because earlier system design methodologies emphasized technical aspects and paid little attention to the organizational problems in an office environment.

The OSSAD project was supported by researchers from France, Germany, Canada, Italy, and Finland. During its development, it was field-tested in all these countries. This field-test process is illustrated in Chapter 5.

A technical specification model provides a detailed description of information system design products, starting from the results of logical design activities that comprise the cycle of creation, refining and selection of solution versions. Chapter 6 constructs a framework for the technical systems specification process and provides a model for the organizational specification process.

Chapter 7 analyzes the motivations for acquiring a tool to support tasks in information systems development. These research results have been collected from real ISD projects. We explain the tool selection criteria, how the characteristics of tools are measured and emphasized in different circumstances according to different states of ISD contingencies, and how the tool selection process could be improved.

Part IV discusses executive information systems (EISs). Various strategic decision-making problems are collected under the same framework in Chapter 8. We classify them by type and strategic level, and analyze the information requirements for solving them. We also discuss information sources of, and techniques and methods for, acquiring this information. Based on this analysis, we identify the types of strategic decision-making problems that could benefit most from the knowledge-based technology in an EIS.

Key issues in the selection and introduction of executive information systems are the following: Can EISs match our managerial needs and support analytical decision making in an organization? How widely can they be introduced at the management level? Are they easy to learn, easy to use, and easily customizable? Do they utilize the most modern information technology, including graphics? Will they work in our computer network? To facilitate finding elegant solutions to the selection problems, we construct and apply in Chapter 9 an evaluation framework that guides the selection of EIS products to match management needs in the organizational contingencies.

Chapter 10 analyzes current practices in the field of management information systems and decision support systems. To improve these systems in supporting executives in decision making, we propose the integration of decision support 
capability into EIS, together with expert systems and knowledge-based systems technology. A conceptual framework for an intelligent executive support system is presented.

Part V discusses mobile computing. The concepts of the traveling executive and executives' mobile information system are defined in Chapter 11. We collected data and opinions from personal discussions with forty-nine executives in the United Kingdom, France, Italy, and Finland, and drew conclusions from the nature of their work and their use of information technology. The expectations of the executives were also analyzed, especially concerning the mobile use of information technology services. Many reasons and cultural characteristics were found to explain differences in these four countries.

Exception handling in an information system is the theme of Part VI. Offices are the dynamic heart of organizations. Interactions, exceptions and interruptions are basic characteristics of office information systems. They are often considered problematic in the formulation of procedures for office workers. In Chapter 12 we analyze the characteristics of exceptionality, reasons for exceptions, organizational influence of exceptions, and exception handling principles and practices in information systems.

Part VII analyzes quality assurance and performance evaluation of information systems. Basic concepts are presented in Chapter 13. Organizational, social, economic, and technical criteria for evaluation, and evaluation practices and user participation, are analyzed. In Chapter 14, graphic models are constructed and analyzed to illustrate the dynamic nature of the performance evaluation process and the gap between information system performance and user preferences. The changing emphases and intensities of performance evaluation efforts during the information system life cycle are discussed. We explain how user views and technical staff views influence the set of performance evaluation criteria along the information system life cycle. Finally, the whole process of performance evaluation of information systems is analyzed in Chapter 15 by describing critically one evaluation process in a large company. A generic model of criteria is constructed, and assessment measures are identified.

\section{Acknowledgments}

Most research contributions to this book are the result of information system science research projects at the University of Jyväskylä in Finland. I am grateful to a number of my colleagues who worked on these projects. Special acknowledgment is due to my coauthors, David W. Conrath, Ph.D., P.Eng., Professor of Management Sciences and Information Systems and Dean at the Michael G. DeGroote School of Business, McMaster University, Hamilton, Ontario, Canada; Esa Auramäki, M.Sc. (Econ.), Development Manager with Solution Garden, Jyväskylä; Mauri Leppänen, Lic. Econ., Professor of Computer Science at the University of Jyväskylä; Shuhua Liu, Lic. Econ, Ph.D. student at Carleton Uni- 
versity, Ottawa, Canada; Kari Partanen, M.Sc. (Econ.), Executive Manager with INTEC, Helsinki; Seppo Puuronen, Ph.D. (Econ.), Senior Lecturer at the University of Jyväskylä; and Heikki Saastamoinen, Ph.D., Director of Information Resource Management and Research and Development Units at ENERMET, Jyväskylä. Furthermore, I am indebted to publishers who granted me permission to use previously published material.

Vesa Savolainen

Jyväskylä, Finland

November 1998 


\section{Credits}

The editor wishes to acknowledge the permissions granted for reprinting texts, figures, and tables in

Chapter 1: ACM, DataBase, vol. 19, no. 1, 1987, pp. 11-20;

Chapter 2: Elsevier Science Publishers, Bullinger (ed.), Human Aspects in Computing, 1991, pp. 1135-1139, and Sol and Crosslin (eds.), Dynamic Modelling of Information Systems, 1992, pp. 285-308; Institutul de Cercetari in Informatica, Studies in Informatics and Control, 1994, vol. 3, no. 4, pp. 285-307;

Chapter 3: Elsevier Science Publishers, Sol and Vecsenyi (eds.), Environments for Supporting Decision Processes, 1991, pp. 129-140;

Chapter 7: Elsevier Science Publishers, Verrijn-Stuart, Sol and Hammersley (eds.), Support Functionality in the Office Environment, 1991, pp. 251-265; Oficyna Wydawnicza Politechnici Wroclawskiej, Systems Science, 1993, vol. 19, no. 2, pp. 43-54;

Chapter 8: Oficyna Wydawnicza Politechnici Wroclawskiej, Bubnicki (ed.), Proceedings of the 12th International Conference on System Science, 1995, pp. 285-295;

Chapter 9: Plenum Publishing Corp., Systems Practice, 1995, vol. 8, no. 5, pp. 537-561;

Chapter 10: Institutul de Cercetari in Informatica, Studies in Informatics and Control, 1994, vol. 3, no. 4, pp. 325-345;

Chapter 11: Blackwell Science Ltd., Information Systems Journal, 1997, vol. 7, pp. 3-20. 


\section{Contents}

Preface vii

Credits xiii

\section{Part I}

Methodologies and Metamodels for Information System Development and Their Evaluation 1

1. Framework for Information Activities 3

Esa Auramäki, Mauri Leppänen, and Vesa Savolainen

1.1. Motivation 3

1.2. Foundations of the Framework 4

1.2.1. Information System and Its Environment 5

1.2.2. Principles of Level Construction 6

1.3. IST, the Fundamental Conceptual Component of Information $\begin{array}{ll}\text { Systems } & 7\end{array}$

1.4. Levels of Information Activity 9

1.4.1. Hierarchical Structure 9

1.4.2. IS Use Level 11

1.4.3. ISD Level 11

1.4.4. ISD Model Construction Level 12

1.4.5. Theory Development Level 12

1.4.6. Interpretations of the Framework 13

1.5. Evaluation 15

1.5.1. Framework for Research 15

1.5.2. Frame of Reference for Tools 16

$\begin{array}{ll}\text { 1.6. Conclusions } & 19\end{array}$

2. Analysis of Three IS and ISD Reference Frameworks 23 Vesa Savolainen

2.1. Related Works 23

2.2. Definitions and Concepts 25

2.3. A Short Description of Three Reference Frameworks 25 
2.3.1. Framework for Understanding 26

2.3.2. HECTOR Framework of Reference $\quad 28$

2.3.3. FRISCO Framework $\quad 31$

2.4. Scheme for Evaluating Metamethodologies 33

2.4.1. Internal Validity of Frameworks $\quad 34$

2.4.2. External Validity of Frameworks $\quad 37$

2.4.3. Coverage of Frameworks $\quad 38$

2.5. Comparison Results 39

2.5.1. Internal Validity of Frameworks $\quad 39$

2.5.2. External Validity of Frameworks 43

2.6. Conclusions 47

\section{Part II}

Contingency Factors and Uncertainty in Decision Making in Information System Development

3. Favorable Atmosphere for Effective Information

Technology Decisions

Vesa Savolainen

3.1. Basic Assumptions

3.2. MISD Contingency Factors

3.3. Main Information Technology Decisions 56

3.4. Priority Setting and Other Strategic Decisions 56

3.5. Feasibility Study, Contingency Analysis, and Methodology Selection

3.6. MIS Implementation Decisions

3.7. Introduction of the New MIS and Maintenance Decisions 60

3.8. Conclusions

61

\section{Part III}

Development of Holistic ISD Methodologies and Selection of ISD Methods and Tools

4. Overview of the OSSAD Methodology 67

David W. Conrath and Vesa Savolainen

4.1. Principles, Functions, and Approach 67

4.2. Main Principles 67

4.3. Approach $\quad 69$

4.3.1. Set Contract $\quad 71$

4.3.2. Analyze Situation $\quad 71$

$\begin{array}{ll}\text { 4.3.3. Design System } & 72\end{array}$

4.3.4. Implement Changes $\quad 74$ 
4.3.5. Monitor System Performance

4.4. Management Issues

4.4.1. Organization

4.4.2. Procedures for Getting Under Way 76

4.5. Modeling

4.6. Language

4.6.1. Abstract Model

4.6.2. Descriptive Model

4.6.3. Specification Models

4.7. Conclusions

5. Refinement of the OSSAD Methodology by Multiclient Field Testing

Mauri Leppänen and Vesa Savolainen

5.1. Overview

5.2. Framework for Research Work

5.2.1. Research Objective

5.2.2. Research Setting

5.3. Research Methods

5.3.1. Study Methods

5.3.2. Experimental Methods $\quad 97$

5.3.3. Action Research 97

5.3.4. Methodological Pluralism $\quad 99$

5.4. Field Test Practice in the Development of OSSAD Methodology 99

5.4.1. The Application of the 7S-Frame to the OSSAD Field Test Practice

5.4.2. The Contextual Framework of the Analysis

5.4.3. Sequence of Methodological Steps

5.4.4. Use and Relevance of Instruments and Procedures, Models and Concepts

5.4.5. Strategic Aspects and Findings on the OSSAD Methodology 104

5.5. Some Results of Other OSSAD Field Testings

6. Technical Specification of an Information System

6.2. Information System Structure and User Interface Specification 114

6.3. Software Specification

6.4. Specification of Files, Databases, and Knowledge Bases 117

6.5. Specification of Data Media, Hardware, and Other Facilities 118

6.6. Specification of Systems Interconnections

6.7. Specification of Information System Quality and Control Features 120

6.8. Framework for Technical Specification Process

6.9. Conclusions 
7. Decision Criteria for Information System Development Tool Selection

Vesa Savolainen

7.1. Types of Tools for Supporting ISD Processes 127

$\begin{array}{ll}\text { 7.2. Reasons for Acquiring a Tool } & 128\end{array}$

7.3. Issues in Selection Processes 130

7.4. Rating Selection Criteria $\quad 130$

7.5. Computerized Support of the Selection Process 133

$\begin{array}{ll}\text { 7.6. Conclusions } & 134\end{array}$

\section{Part IV}

\section{Toward Intelligent Executive Information Systems}

8. Strategic Decision Making

Vesa Savolainen and Shuhua Liu

8.1. Motivation for Classifying Decision Problems

8.2. Classification of Strategic Decision-Making Problems

8.3. Analysis of Information Requirements

8.4. Decisions Supported by Knowledge-Based Technology

9. Evaluation of Executive Information Systems

\section{Kari Partanen and Vesa Savolainen}

9.1. Acquiring an EIS Product to Match the Managerial Requirements

9.2. Development of Mangerial Support Systems

9.2.1. Management Information Systems

9.2.2. Decision Support Systems

9.2.3. Executive Information Systems

9.2.4. Generalization Trends in Information Systems for Managerial Use

9.3. Framework for Evaluating EIS Products 157

9.4. Functional Capabilities of EIS Products 159

9.5. Qualitative Properties of EIS Products 161

9.6. Technical Properties of EIS 163

9.7. Cost Issues 164

9.8. User's Experiences 164

9.8.1. Utilization of the Functional Properties of EIS 165

9.8.2. Utilization of the Qualitative Properties of EIS 167

9.8.3. Utilization of the Technical Properties of EIS 168

9.9. Issues in Construction, Introduction, and Use of EIS 168

$\begin{array}{ll}\text { 9.10. Conclusions } & 169\end{array}$ 
10. Application of Knowledge-Based Technology in Executive Information Systems

Shuhua Liu and Vesa Savolainen

10.1. The Diversity of Decision Support Systems 173

10.2. DSS, EIS, and ESS

10.2.1. Decision Support Systems 175

10.2.2. Executive Information Systems 177

10.2.3. Executive Support Systems 179

10.3. IESS as an Integration of ES/KBS Technology to EIS and DSS 180

10.3.1. Expert Systems and Knowledge-Based Systems $\quad 180$

10.3.2. Intelligent Decision Support Systems 183

10.3.3. Intelligent Executive Support Systems 185

10.4. Structure of Intelligent Executive Support Systems 186

10.4.1. The Interface 189

10.4.2. Office Support Subsystem $\quad 189$

10.4.3. Database Subsystem 189

10.4.4. Model Base Subsystem 189

10.4.5. Knowledge Base Subsystem 190

10.4.6. Work Space 191

10.5. Conclusions 192

\section{Part V}

Mobile Information Systems 195

11. Executives' Views of Mobile Information Services 197

Seppo Puuronen and Vesa Savolainen

11.1. Concepts, Research Objectives, and Research Methods 197

$\begin{array}{ll}\text { 11.1.1. Basic Concepts } & 198\end{array}$

11.1.2. Research Objectives 198

11.1.3. Research Methods 199

11.2. Executives' Work 199

11.2.1. Main Characteristics of Executives' Work 199

11.2.2. Trends 200

11.2.3. Our Case Studies of Executives 200

11.2.4. Time Distribution of Executives' Work 201

11.3. Information Technology Support for Executives' Tasks 202

11.3.1. Personal Work Support 202

11.3.2. Mail and Communication Services 202

11.3.3. Information Services $\quad 204$

11.3.4. Office Support Services $\quad 204$

11.3.5. Analytical Support Services 204

11.3.6. Other Services 205

11.3.7. IT Use Experiences and the Executives' Tasks 205 
11.4. Trends in Information Technology Support for Executives

11.4.1. Value-Added Services

11.4.2. Executives' Expectations of Mobile IT Services

\section{Part VI}

Exception Handling in Information Systems

12. Basic Concepts of Exception Handling in Office Information Systems

Heikki Saastamoinen and Vesa Savolainen

12.1. Event Handling

12.2. Dynamic Nature of Office Information Systems

12.2.1. Office

12.2.2. Rules

12.2.3. Exceptions

12.3. Characteristics of Exceptionality

12.3.1. Severity Classes of Exceptions

12.3.2. Frequencies of Exceptions

12.3.3. Organizational Influence of Exceptions

12.3.4. Reasons for Exceptions

12.4. Exception Handling Principles

12.4.1. Event Handling

12.4.2. Action Analysis

12.4.3. Handling of Established Exceptions

12.4.4. Handling of Otherwise Exceptions

12.4.5. Handling True Exceptions

12.5. Exception Handling in Organizations

12.5.1. Levels of Information Systems

12.5.2. Exception Handling Practices

12.5.3. Consequences of Exception Occurrence 233

12.6. Conclusions

\section{Part VII}

Quality Assurance and Performance Evaluation of Information Systems

13. Concepts and Practices in Performance Evaluation of Office Information Systems

Vesa Savolainen

13.1. System Performance and Changing User Preferences

13.2. Concepts and Criteria 
13.2.1. Main Concepts

13.2.2. Evaluation Criteria in OSSAD Models

13.2.3. Evaluation of the OIS Development Process and Its Results 244

13.2.4. Organizational, Social, Economic, and Technical Criteria for the Evaluation

13.3. Framework for Dynamic OIS Evaluation

13.4. Evaluation Practices and User Participation

14. Analysis of the Dynamic Nature of Information Systems Performance Evaluation

Vesa Savolainen

14.1. Theoretical Background and Research Issues

14.1.1. Theoretical Foundations and Research Methodology

14.1.2. Research Issues

14.2. Evaluation from the Systems Developers' Viewpoints

14.3. Changing Interest in Systems Evaluation Through the ISLC

14.4. Changing Evaluation Criteria Throughout the ISLC

15. Performance Evaluation of an Information System:

An Experiment

Vesa Savolainen

15.1. Background for Our Case Studies

15.2. Performance Evaluation Process

15.3. Performance Evaluation Criteria and Measurement 